\title{
Analysis on Semantic Relations of English Nominal Anaphora
}

\author{
Xu Yuqing \\ Xiamen University Tan Kah Kee College \\ Zhangzhou, Fujian, China
}

\begin{abstract}
Anaphora plays an indispensable role in discourse cohesion since it tells us how discourse is constructed and arranged. The present paper aims to analyze anaphora from a semantic angle. In this paper, definition and types of anaphora are presented firstly, and then moves to focus on nominal anaphora. Through analyzing these English nominal anaphoric phenomenons, semantic relations between anaphoric elements and their antecedents such as synonymy, hyponymy and meronymy are found out between these sentences. Finally, some enlightenment with regard to English teaching and learning are provided.
\end{abstract}

Keywords-anaphora; nominal anaphora; semantic relation; College English Teaching

\section{INTRODUCTION}

Anaphora has received a great deal of attention from linguistics because they tell us how discourse is constructed and arranged. Early in the work of Halliday\&Hasan [1], they saw text as a semantic unit in the context of the systemic-functional theory which is developed by Halliday. Halliday\&Hasan argue that language performs three macro-functions - the "Ideational", "Experiential" and "Textual" functions. The textual function is concerned with the ways in which languages construct messages and texts. According to Halliday\&Hasan, well-formed texts must display the property of cohesion - that is, they must be semantically well-constructed and coherent linguistic units and cohesion fits into this function as the set of surface means by which texts and messages are constructed as semantically coherent entities. They proposed a detailed typology of the different linguistic markers of cohesion in English. Relationships between two or more meanings in a text are referred to by Halliday\&Hasan as cohesive "ties", usually by linguistic units such as pronouns and definite noun phrases. They distinguish between "endophora", where an antecedent is textual, and "exophora", where an antecedent is found outside the text. Endophora is further divided into anaphora (backward dependency) and cataphora (forward dependency), substitution, where an antecedent is directly substituted for one of a closed class of marker words, and ellipsis, where a gap in the structure of one sentence may be interpreted by reference to a constituent in another sentence.

\section{ANAPHORA}

\section{A. Definition of anaphora}

Anaphora comes form Greek, referring to 'up': that is to something earlier. Botley\& McEnery [2] define anaphora as "a phenomenon where the interpretation of a given meaning depends on the existence in the preceding linguistic context of an expression of the same meaning." They use a classic example of Halliday\&Hasan to illustrate this "backward dependency": Wash and core six cooking apples. Put them in a fire-proof dish. In this example, the plural pronoun them in the second sentence can be interpreted as referring backwards to six cooking apples in the first sentence, i.e. the anaphoric tie are them and the antecedent six cooking apples.

Oxford Concise Dictionary of Linguistics [3] gives a simpler and clearer definition for anaphor, "the relation between a pronoun and another element, in the same or in an earlier sentence that supplies its referent." The dictionary uses an example to illustrate the definition: Mary disguise herself, here the reflexive pronoun herself is understood as anaphoric to Mary: that is, it refers to whoever Mary refers to. Likewise, in conversation, if A asks 'Where's Mary?' and B says 'She's in the garden', She in the sentence B utters is meant to be understood as anaphoric to earlier Mary. The dictionary further points out that other words or phrases expect pronouns can be anaphoric elements: e.g. the idiot is anaphoric to John in I asked John but the idiot wouldn't tell me; do so is anaphoric to help in I want to help but I couldn't do so.

In short, anaphora is the relationship between one word and another word or phrase, is an expression "referring" back to the antecedent.

\section{B. Types of anaphora}

In English, anaphora can be realized by many different linguistic markers, such as pronouns, demonstrative pronouns, pronominal substitutions or ellipses. We often use pronouns such as she, he, it, his, her and their to refer to earlier items; we also use demonstratives such as the, this, that, and those for anaphorical purposes; we use substitution to replace one lexical item with another as an alternative to repeating the first; and ellipsis, also called zero anaphora, is a special case of substitution in which we "substitute" one phrase with nothing. Zero anaphora is also described as "referring back" to an expression that supplies the information necessary for interpreting the gap. The following examples will illustrate some of these different types of anaphora. 


\section{Anaphora involving pronouns:}

(1) The woman lost track of her little boy at the mall. She became very worried.

(2) The man had a rich son. He was ashamed of his father, and never came to see him.

(3) My hometown is Guilin. It is very beautiful.

\section{Anaphora involving demonstrative determiners:}

(4) For them the washwoman's absence was a trouble. They needed the laundry. They did not even know the woman's address.

(5)The clothes designed in our company are more fashionable than those designed in their company.

(6) "It is no great matter to me," Hotchkiss concluded, "for I had only the wages of my Portland engagement, and that was no great sum, I assure you". [2]

\section{Anaphora involving pronominal substitutions:}

(7) My smart phone is too old and slow. I need to get a new and faster one.

(8) The computer is considered a necessity. It has been so since the 1990s.

(9) $\mathrm{He}$ is an outstanding entrepreneur and he is anywhere regarded as such.

\section{Anaphora involving ellipses:(ellipses marked by 0)}

(10) I wish I had more talent. My brother has a lot more 0 than I do.

(11) We wanted fried egg, but they gave us boiled 0 .

(12)The boy wanted to play his football in the street, but his father told him not to 0 .

\section{NOMINAL ANAPHORA}

Pronouns, demonstrative pronouns, pronominal substitutions and ellipses are often ways by which the discourse is connected. In this part, examples of English nominal anaphora will be focused on and some semantic relations between anaphoric words and their antecedents include synonymy, hyponymy and meronymy are analyzed as well.

\section{A. Synonymy}

A synonym is a word which has the same or very similar meaning as another such as boy and lad, lawyer and attorney, cookie and biscuits, underground and subway, etc. Synonyms are used in sentences to achieve cohesion; they also serve function of anaphora.

(13) Accordingly..., I took leave, and turned to the ascent of the peak. The climb is perfectly easy.... [1]

(14) I saw a boy win the spelling bee. The lad was delighted afterward. [4]

(15) Three models have been developed to explain these results. The active search logogen and cohort models can each describe some of the findings. [4]
In (13), climb and ascent are synonyms; both are nouns and contain meanings of going up. The climb in the following sentence refer back to the ascent in the first sentence. Likewise, we identify that in (14)\&(15), boy and lad; results and findings are synonyms, lad and findings anaphorically refer back to their antecedents boy and results respectively. From above examples, we may say semantic relations between sentences are connected through synonyms. As Zhu [5] points out, principle of synonyms facilitates construction and understanding of discourse by two or more than two different words which contain similar meanings.

\section{B. Hyponymy}

According to Saeed [6], hyponymy is a relation of inclusion. A hyponym includes the meaning of a more general word. He uses examples to illustrate: dog and cat are hyponyms of animal; sister and mother are hyponyms of woman. The more general term is called the superordinate while the more specific one is called subordinate, like Figure 1 below:

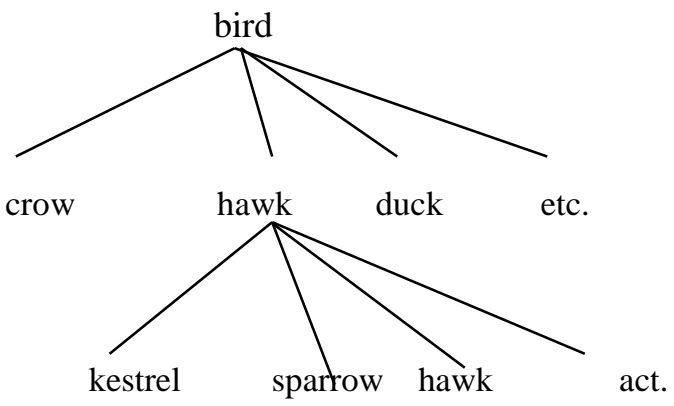

Fig. 1 Hyponymy relationship between anaphoric(Source: Based on Semantics, by John. L. Saeed [6])

Here kestrel is a hyponym of hawk, and hawk a hyponym of bird. We assume that the relationship is transitive so that kestrel is a hyponym of bird, like the chart below:

There are two situations as for the appearance of hyponyms. One is superordinate word appears first then comes to the subordinate one.

(16) He wished for the thousandth time in his life that he had a dog, a golden retriever, maybe, for travels like this and to keep him company at home. [5]

(17) Marian had dreams of becoming a musician, a folksinger. [5]

In (16), a dog is a general word; retriever is a kind of dog. In this sentence, retriever anaphorically refers back to dog, the semantic relation between dog and retriever is hyponymy. Also, a musician and a folksinger in (17) also construct intra-sentential hyponymy semantic relations. The other case of hyponymy is the superordinate word comes followed by suberordinate one. The following examples are from Lian [7]:

(18) The monkey's most extraordinary accomplishment was learning to operate a tractor. By the age of nine, the monkey had learned to solo on the vehicle. 
(19) John's bought himself a new Ford. He practically lives in the car.

(20) I don't know where to stay when I arrive in Shanghai, I have never been to that place.

If we identify the semantic relationship between anaphoric noun phrase the vehicle and its antecedent a tractor in (18), firstly, tractor is a vehicle used on farms, for example to pull machines. From the definition we know that tractor is a vehicle. Figure 2 illustrates the clear relationship between tractor and vehicle.

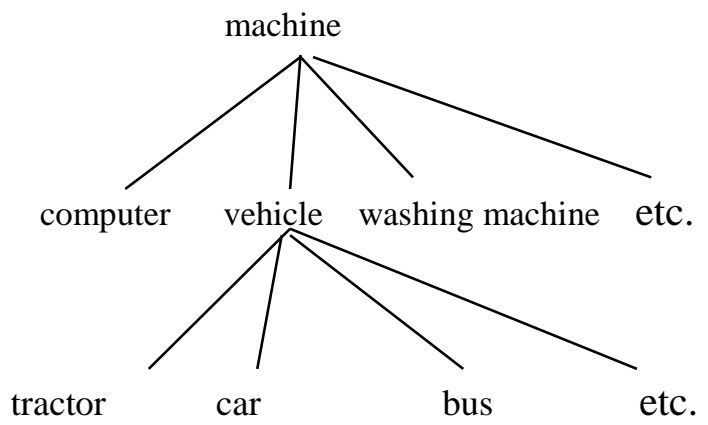

Fig. 2 Semantic relationship between anaphoric

From the above chart, we can clearly see that machine is a superordinate word. In the comparatively large lexical field of machine, computer, vehicle and washing machine are included. Tractor, car and bus belongs to subordinate words of vehicle. Tractor and vehicle are in the same lexical field. Thus we may say tractor is a hyponym of vehicle, and vehicle a hyponym of machine. Similarly, we can infer that in (19), Ford is a hyponym of car since based on common knowledge we know Ford is a car brand, which comes from Ford motor company, a famous motor company, manufactures and distributes automobiles in world markets. The car anaphorically refers back to its antecedent Ford. In (20), the relationship between that place and its antecedent Shanghai is hyponymy, Shanghai is a hyponym of that place. In the semantic field of place, different places from all over the world, no matter big or small ones all belong to this lexical field. From the sentence when I arrive in Shanghai, we believe that here Shanghai can be identified as the famous Chinese city. Direct relationship exists between Shanghai and place in the lexical field of place. Thus we can identify that in sentence (20), the anaphoric determinate noun phrase that place refers back to its antecedent Shanghai.

Definite noun phrases not only have functions of anaphora but also show the semantic relationship, here hyponymy relationship, between the anaphoric elements and their antecedents. Through this connection, readers will be more easily to understand and infer the meaning of sentences. That is to say, any two lexicons in language can be relevant through direct or indirect relationship in lexical field. The hyponym relationship between lexicons plays a crucial role in inference of antecedents and anaphoric noun phrases.

\section{Meronymy}

Besides hyponym relationship between anaphoric noun phrases and their antecedents are identified, another common semantic phenomenon is meronymy According to Saeed [6], who defines meronymy as a term used to describe a part-whole relationship between lexical items. He gives example: cover and page are meronyms of book. The relationship can be described as $\mathrm{X}$ is part of $\mathrm{Y}$, or $\mathrm{Y}$ has $\mathrm{X}$. Thus we can identify the relationship between page and book as A page is part of a book, or A book has pages. Saeed uses the following chart to illustrate the hierarchical relationship in the lexicon:

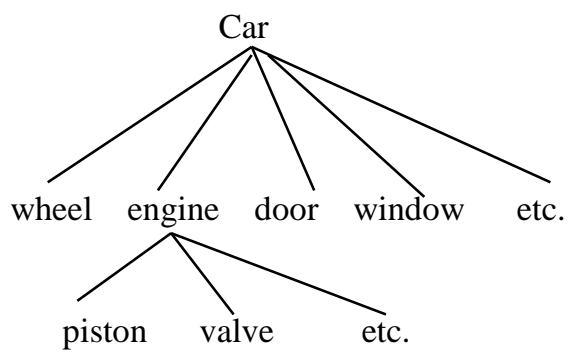

Fig. 3 Meronymy relationship between anaphoric (Source: Based on Semantics, by John. L. Saeed [6])

This chart shows the part-whole relationship between parts of car and the general item car. As we know a car has wheel, engine, door, window, etc. Thus, it is true to say Wheel, engine, door and window are part of a car, or A car has wheel, engine, door, window, etc. Thus Wheel, engine, door and window are meronym of car. The chart shows another more specific example; an engine is divided into piston, valve, etc. Likewise, we may say An engine has piston, valve, etc. Or Piston, valve are part of an engine. The relationship between piston, valve and engine is also part-whole relationship. Piston, valve are meronym of engine.

As mentioned, hyponymy is transitive, we may say A vehicle is a kind of machine; A tractor is a kind of vehicle; then we infer that $A$ tractor is a kind of machine. The relationship among them is transitive. Unlike hyponymy, Saeed claims that meronymy differs from hyponymy in transitivity. Hyponymy is always transitive, as we know above, but meronym may or may not. He adopts the following transitive and non-transitive examples to explain: nail as a meronym of finger, and finger of hand. We can see that nail is a meronym of hand, for we can say a hand has nails. Pane is a meronym of window (a window has a pane), and widow of room (a room has a window); but pane is not a meronym of room, for we cannot say $\mathrm{A}$ room has a pane. Another non-transitive example is: hole is a meronym of button, and button of shirt, but we can not say that hole is a meronym of shirt.

Example (21) and (22) shows meronymy relationship between anaphoric words and their antecedents.

(21) I walked into a room. The window was broken. 
(22) The book is largely concerned with writing about Chinese language numbers. The last chapter gives advice about speaking with Chinese language numbers.

In (21), The window anaphorically refers back to the antecedent room in the first sentence. The semantic relationship between noun phrases the window and the antecedent room does not belong to hyponymy. From daily life experience, we know that window is a part of room or a room has windows. Besides window, a room may have other parts, such as ceiling, floor, wall, door, etc. Thence, the semantic relationship between window and room is meronymy, window is a meronym of room. The window not only functions as anaphora but also form its semantic relationship with its antecedent. Similarly, in (22), chapter in the second sentence refers to chapters of the book in the first sentence. As we know chapter is a part of book. Here the semantic relationship between anaphoric word chapter and its antecedent the book are meronymy; chapter is a meronym of the book.

\section{Enlightenment to teaching and learning}

From above mentioned, we know that one way to achieve discourse cohesion is by synonyms. Actually, synonym is a kind of substitution, which is used quite a lot in English. As Quirk[8] notes, substitution is one of main principles in English writing and speaking. But substitution is merely not repetition, is a device for abbreviating and for avoiding repetition. As we focus on noun synonyms in the present paper, we have some enlightenment in our English teaching and learning. Firstly, we teachers may pay attention to the principle of synonyms in teaching English. Synonyms are not only words containing same or similar meaning; they serve anaphoric functions and aid to get the discourse connected. Secondly, when explaining synonyms to students, the concept of register must not be ignored, whether the word is formal, colloquial or literary. Thirdly, through contrastive methods, teachers can compare Chinese language and English to inform students that English tends to use more substitution than Chinese does, synonyms is a way of substitution. Students need to be encouraged to use proper substitution in their speaking and writing. As students, the awareness of mastering the knowledge of synonyms and properly use substitution can highlight their speaking and writing. Besides synonyms, lexical field is enlightenment to our teaching and learning, it tells us that knowing the semantic relations among words can strengthen our understanding of lexicon and associative method is an effective way to learn vocabulary.

\section{CONCLUSION}

In conclusion, the present paper discusses phenomenon of anaphora and semantic relations reflected by these anaphora examples. English discourse cohesion can be achieved by many types of anaphora such as pronouns, demonstrative pronouns, pronominal substitutions or ellipses. We focus on nominal anaphora, through analyzing these nominal anaphora examples, semantic relations such as synonymy, hyponymy and meronymy embedded between sentences appear.

\section{REFERENCES}

[1] Halliday, M.A.K., and Ruqaiya Hasan. Cohesion in English. London: Longman, 1976

[2] Botley Simon\& Anthony Mark McEnery, eds. Corpus-based and Computational Approaches to Discourse Anaphora. vol. 3. Amsterdam: John Benjamins Publishing Company, 2000.

[3] P.H. Matthews, "anaphora". Oxford Concise Dictionary of Linguistics. Ed. Shanghai: Shanghai Foreign Language Education Press, 2000.

[4] Carroll, David W. Psychology of Language. Beijing: Foreign Language. Teaching\& Research Press, 2000.

[5] Zhu Yongsheng, Zhen lixin Miao xinwei, A Constrastive Research on Textual Cohesion in English, Shanghai: Shanghai Foreign Language Education Press, 2000.

[6] Saeed, John. L. Semantics. Beijing: Foreign Language Teaching\& Research Press, 2000.

[7] Lian Shuneng, A Contrastive Study of English and Chinese, Beijing: Higher Education Press, 1993

[8] Quirk, R, S.Greenbaum, G.Leech and J.Svartvik. A Grammar of Contemporary English. Longman, 1973. 